\title{
Performance of Pre-Stressed Sandwich Composites Subjected to Shock Wave Loading
}

\author{
E. Wang, and A. Shukla ${ }^{\mathrm{a}}$ \\ Dynamic Photomechanics Laboratory, Dept. of Mechanical, Industrial and Systems Engineering \\ University of Rhode Island, 92 Upper College Rd, Kingston, RI, 02881, USA
}

\begin{abstract}
The present paper experimentally studies the dynamic behaviour of prestressed sandwich composites under blast loading. The in-plane static compression loadings are implemented on the sandwich composites before they are subjected to the transverse shock wave loading. Three different pre-stress levels are chosen. 3-D realtime deformation data are captured by two high-speed photography systems: a backview Digital Image Correlation (DIC) system and a side-view camera system. The results show that pre-stresses can induce local buckling in the front face-sheet of sandwich composites, consequently reduce the blast resistance of sandwich composites.
\end{abstract}

\section{Introduction}

Ship hull structures always undergo longitudinal compressive loading and their longitudinal strength is the most fundamental and important strength to ensure the safety of a ship structure [1]. When these pre-stressed structures are subjected to transverse blast loading, the coupling of the in-plane pre-load and transverse blast loading will likely reduce the blast resistance of marine structures.

The dynamic responses of in-plane pre-stressed composite structures under low-velocity transverse impact have been studied. Heimbs et al.[2] tested carbon-fibre/epoxy laminated plates under an in-plane compressive pre-load. An increased deflection and energy absorption was observed under a pre-load of $80 \%$ of the buckling load. Sun et al. [3] and Choi [4] analytically investigated the effects of pre-stress on the dynamic response of composite laminates. They found that the initial in-plane tensile load increased the peak contact force while reducing the total contact duration and deflection. The compressive load reacted oppositely. However, the most recent research on composite structures focuses only on the blast resistance without any in-plane pre-load. There are very few theoretical and numerical studies [5] related to the blast response of pre-stressed structures. To date no experimental investigations on pre-stressed structures under blast load have been done.

The present paper experimentally studies the dynamic behaviour of pre-stressed sandwich composites under blast loading. A special fixture is designed in order to enable different in-plane static compression loading on the sandwich composites before they are subjected to the same level transverse shock wave loading. Three different pre-stress levels are chosen to study the effect of the pre-stress on the dynamic response of the sandwich composites. A back-view Digital Image Correlation (DIC) system and a side-view camera system are utilized to capture 3-D real-time

\footnotetext{
a e-mail : shuklaa@egr.uri.edu
}

This is an Open Access article distributed under the terms of the Creative Commons Attribution-Noncommercial License 3.0, which permits unrestricted use, distribution, and reproduction in any noncommercial medium, provided the original work is properly cited. 
deformation of the specimen. These results are used to analyze the mechanism of dynamic failure of the pre-stressed sandwich composites.

\section{Materials and specimens}

The skin materials that were utilized in this study are E-Glass Vinyl Ester (EVE) composites. The woven roving E-glass fibres of the skin material were placed in a quasi-isotropic layout [0/45/90/$45]_{s}$. The fibres were made of the $18 \mathrm{oz} / \mathrm{yd} 2$ area density plain weave. The resin system used was Ashland Derakane Momentum 8084 and the front skin and the back skin consisted of identical layup and materials. The core material used in the present study was Corecell ${ }^{\mathrm{TM}}$ P600 styrene foams, which is manufactured by Gurit SP Technologies specifically for blast defence applications. Table 1 lists important material properties of this foam from the manufacturer's data [6].

Table 1. Material properties of foam core [6].

\begin{tabular}{|c|c|c|c|c|}
\hline & $\begin{array}{c}\text { Nominal } \\
\text { Density } \\
\left(\mathbf{k g} / \mathbf{m}^{\mathbf{3}}\right)\end{array}$ & $\begin{array}{c}\text { Compression } \\
\text { Modulus } \\
\text { (MPa) }\end{array}$ & $\begin{array}{c}\text { Compression } \\
\text { Strength } \\
(\mathbf{M P a})\end{array}$ & $\begin{array}{c}\text { Shear } \\
\text { Elongation } \\
\mathbf{\%}\end{array}$ \\
\hline $\begin{array}{c}\text { CoreCell } \\
\text { P600 }\end{array}$ & 122 & 125 & 1.81 & $67 \%$ \\
\hline
\end{tabular}

The VARTM procedure was carried out to fabricate sandwich composite panels. The overall dimensions for the specimen were $102 \mathrm{~mm}$ wide, $254 \mathrm{~mm}$ long and $33 \mathrm{~mm}$ thick. The foam core itself was $25.4 \mathrm{~mm}$ thick, while the skin thickness was $3.8 \mathrm{~mm}$. The average areal density of the samples was $17.15 \mathrm{~kg} / \mathrm{m} 2$. Fig. 1 shows a real image of a specimen and its dimensions.

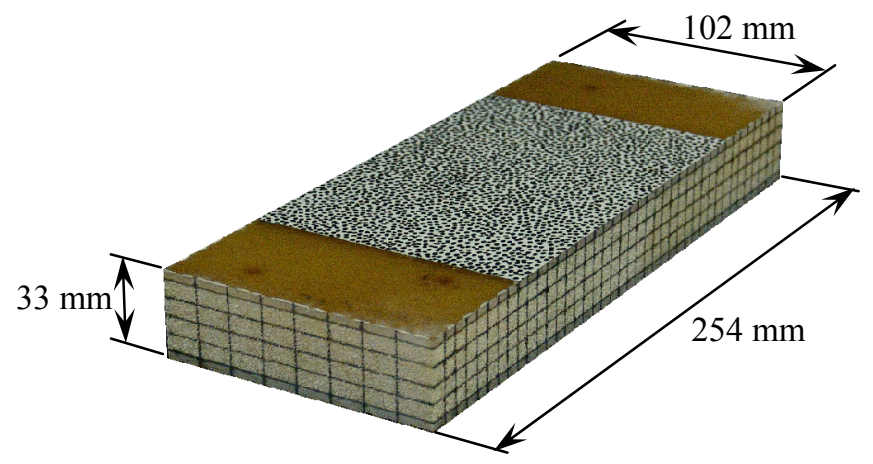

Fig. 1. The sandwich specimen and over all dimensions.

\section{Experimental setup and procedure}

\subsection{Shock tube}

The shock tube apparatus was utilized in present study to obtain the controlled blast loading. The detail of this apparatus can be found in Ref.[7]. Fig. 2 shows the shock tube apparatus with muzzle detail. The final muzzle diameter is $76.2 \mathrm{~mm}$. Two pressure transducers (PCB102A) are mounted at the end of the muzzle section with a distance $160 \mathrm{~mm}$. The support fixtures ensure simply supported boundary conditions with a $152.4 \mathrm{~mm}$ span. 


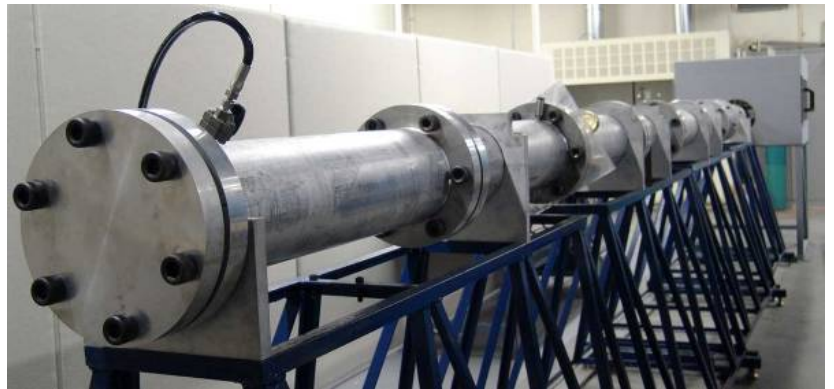

(a) Shock tube

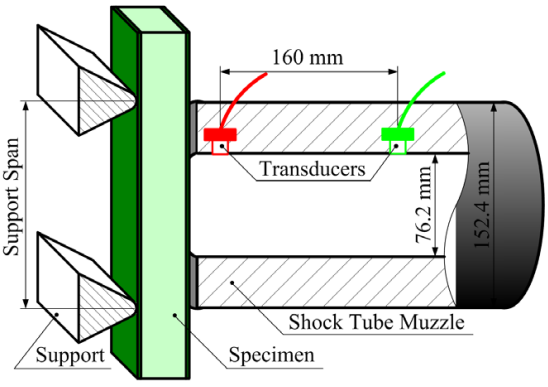

(b) Muzzle detail and specimen

Fig. 2. Shock tube apparatus.

\subsection{Pre-loading fixture}

Fig. 3 shows the fixture used to apply the in-plane static compression loading on the sandwich composite panels. The loading head is connected to a hydraulic loading cylinder, which is mounted on the frame. An aluminium cylinder with an outer-diameter $\varnothing 50.8 \mathrm{~mm}$ and an inner-diameter Ø38.1 $\mathrm{mm}$ is positioned between two plates. Two strain gages, which are attached on this aluminium cylinder, measure the deformation of this cylinder and then calculates the load applied on the specimen. The support fixture and in-plane pre-loading fixture are all securely fastened inside a dump tank.

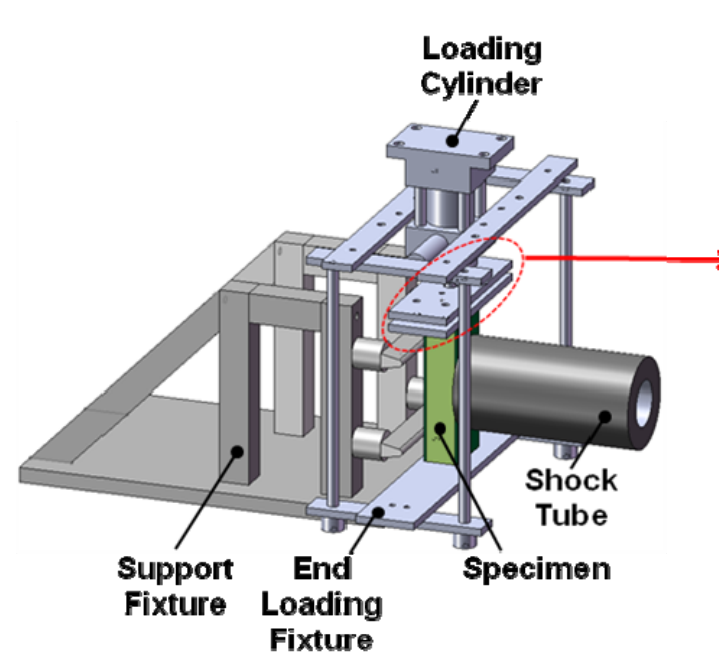

(a) Fixture assembling

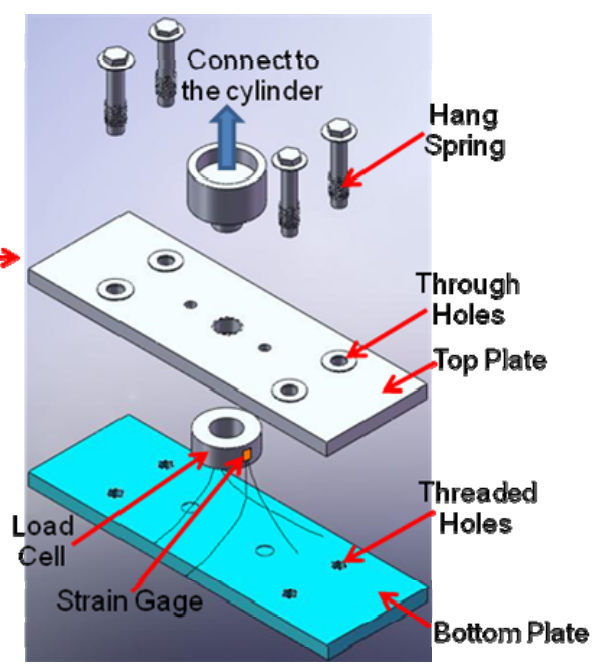

(b) Load head

Fig. 3. Pre-loading fixture.

\subsection{High-speed photography systems}

Two high-speed photography systems were utilized to capture the real-time 3-D deformation data of the specimen. Fig. 4 shows the experimental setup. It consisted of a back-view 3-D Digital Image Correlation (DIC) system and a side-view camera system. All cameras used in the systems are Photron SA1 high-speed digital cameras. They have an ability to capture images at a frame-rate of 
$20,000 \mathrm{fps}$ with an image resolution of $512 \times 512$ pixels for a 1 second time duration. These cameras were synchronized to make sure that the images and data can be correlated and compared.

The 3-D DIC technique is one of the most recent non-contact methods for analyzing full-field shape, motion and deformation. The working mechanism of this technique is similar to how our eyes function. Two cameras capture two images from different angles at the same time. By correlating these two images, one can obtain the three dimensional shape of the surface. Correlating this deformed shape to a reference (zero-load) shape gives full-field in-plane and out-of-plane deformations. To ensure good image quality, a speckle pattern with good contrast was put on the specimen prior to experiments.

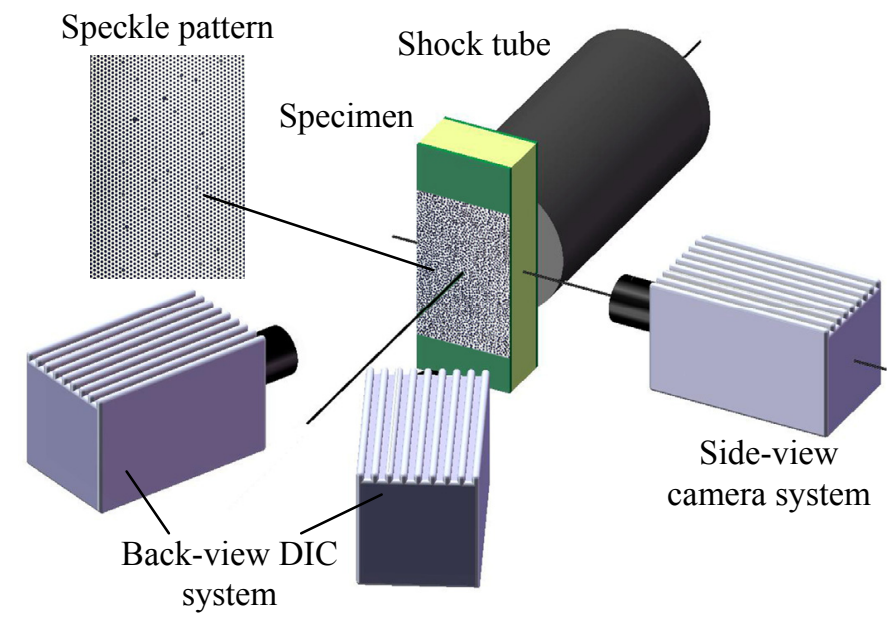

Fig. 4. High-speed photography system.

\subsection{Experimental procedure}

In the present study, the shock wave loading, generated by the shock tube, has an incident peak pressure of approximately $1 \mathrm{MPa}$ and a wave velocity of approximately $1030 \mathrm{~m} / \mathrm{s}$. The in-plane compression loading was applied on the specimen and held at a constant level until the specimen is subjected to the transverse shock wave loading. Three levels of static compression loading were chosen: $0 \mathrm{kN}, 15 \mathrm{kN}, 25 \mathrm{kN}$. For each compression loading, at least two samples were tested. When the shock wave was released, the computer and high-speed photography system were triggered to record the pressure data and deformation images.

\section{Experimental results and discussion}

\subsection{Real time deformation data from high-speed photography system}

Fig. 5 shows the real time deformation images of sandwich composites with different levels of compression pre-loading. The shock wave propagates from the right side of the image to the left side. Some deformation details are pointed out in the images.

From the images, it can be clearly seen that for the sandwich composite without pre-loading ( 0 $\mathrm{kN}$ ), the front face-sheet shows a profile with a smooth and symmetrical curvature. This means there is no local buckling in the front face. For the sandwich composite with $15 \mathrm{kN}$ pre-loading, the section of the front face-sheet, close to the lower support, exhibits more curvature than the section close to the upper support. This asymmetrical phenomenon means that there is a local buckling at the low section of the front face-sheet. At approx $1600 \mu \mathrm{s}$, the fibers debonding of the front face-sheet shows clearly that local buckling is evident. For the sandwich composite with $25 \mathrm{kN}$ pre-loading, 
there are two obvious kinks in the front face-sheet. This means that the local buckling happened in two positions of the front face-sheet.
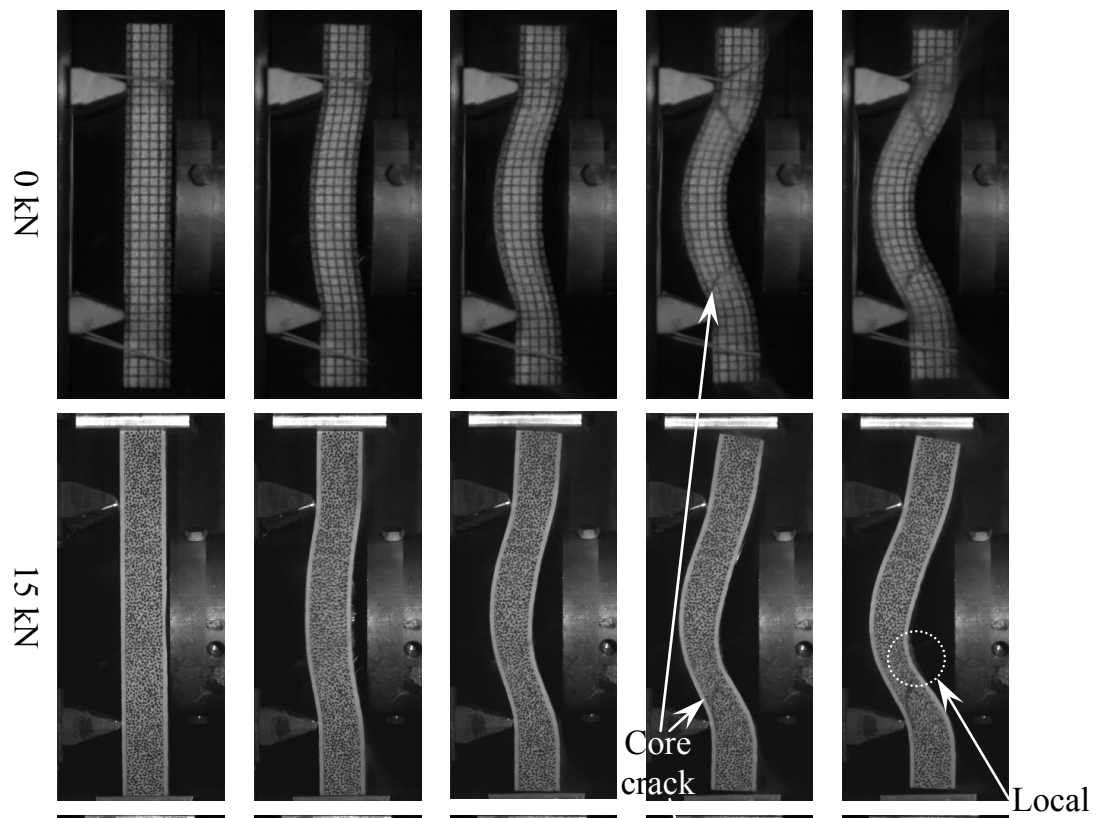

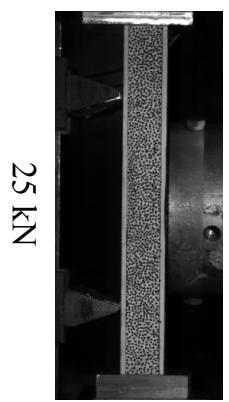

$0 \mu \mathrm{s}$

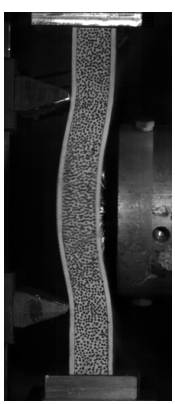

$400 \mu \mathrm{s}$

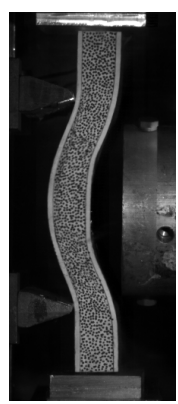

$800 \mu \mathrm{s}$

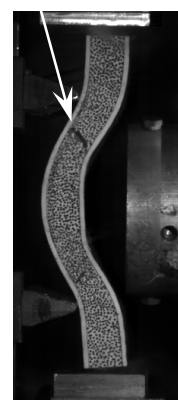

$1200 \mu \mathrm{s}$

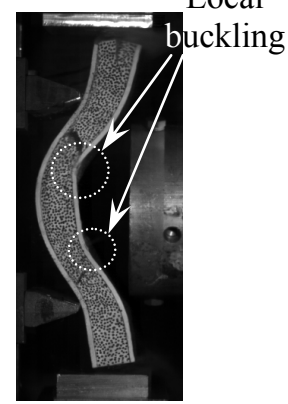

$1600 \mu \mathrm{s}$

Fig. 5. Real time deformation of sandwich composites with different pre-loading.

Fig. 6 shows the back face deflection contours of sandwich composites with different levels of compression pre-loading from DIC technique. It can be seen that the deflections of the panels with 0 and $15 \mathrm{kN}$ pre-loading are very similar. The panel with $25 \mathrm{kN}$ pre-loading has higher deflection.

\subsection{Deflections and in-plane strains}

Fig. 7 shows the deflections of the middle point located on the front and back faces from the sideview high-speed images. From the plots, the defections of the front and back faces for each panel are almost overlapped. This means that there is no core compression in the core thickness direction. The panels with 0 and $15 \mathrm{kN}$ pre-loading have similar deflections while the deflection of the panel with $25 \mathrm{kN}$ pre-loading is higher. Fig. 8 shows the in-plane strain $\mathrm{e}_{\mathrm{yy}}$ of the middle point of the back face from the DIC technique. Here, the vertical direction is y axis. Though the deflections are almost identical, the back-face in-plane strain of the panel with $15 \mathrm{kN}$ pre-loading is much higher than that with $0 \mathrm{kN}$ pre-loading. This shows that the in-plane pre-loading reduces the blast resistance of the sandwich composites. 


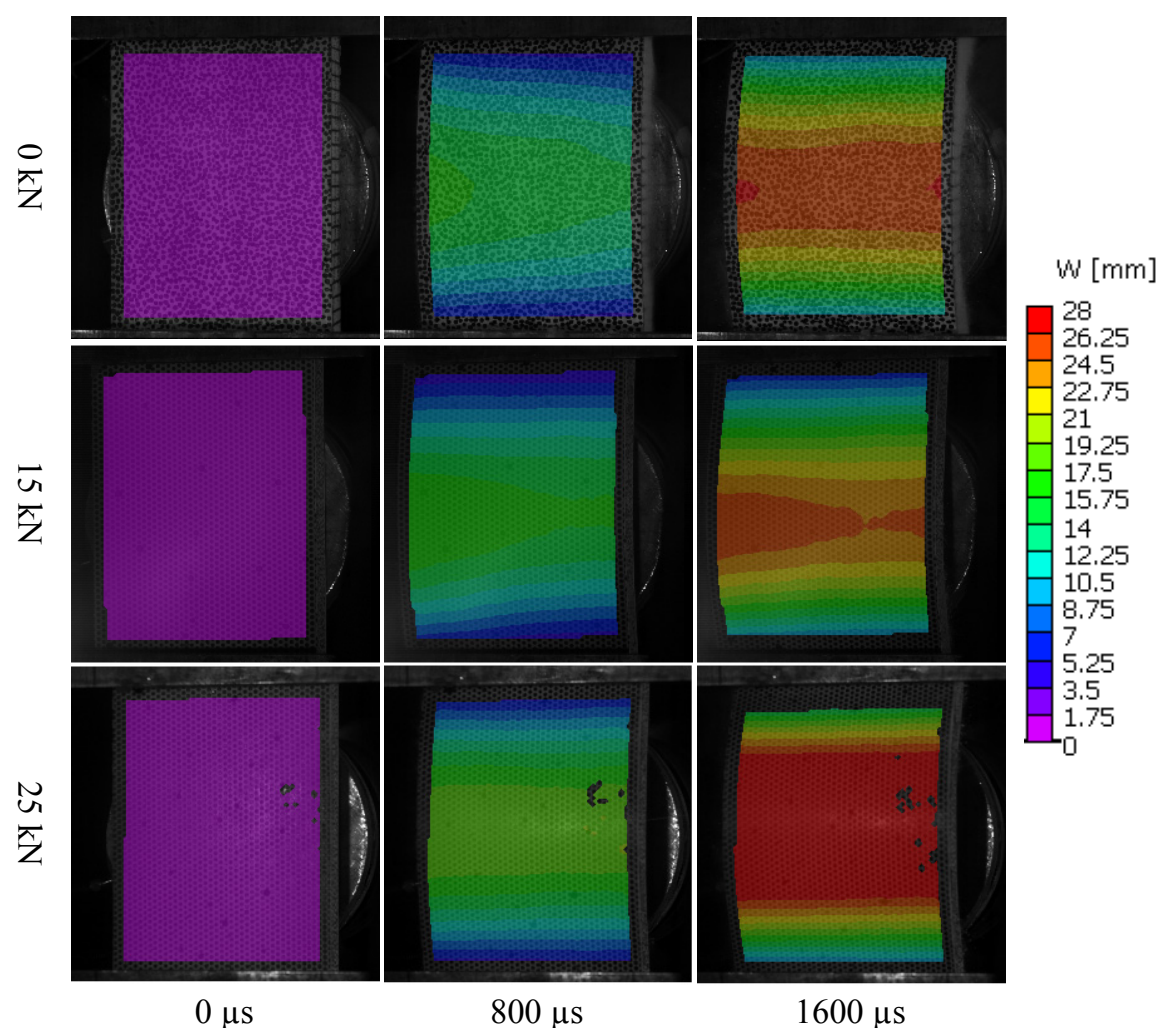

Fig. 6. Real-time full-field back-face deflection contour of sandwich composites with different pre-loading.

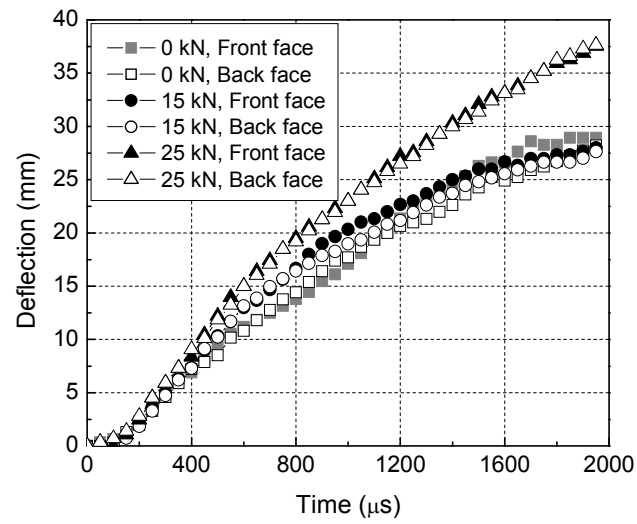

Fig. 7. Deflection of middle point at back and front faces.

\subsection{Post mortem analysis}

The damage patterns of the sandwich panels after the shock event occurred were visually examined and recorded using a high resolution digital camera and are shown in Fig.9. Since the back faces don't show any change after the experiments, only the front face and side view images are shown here. From the front face-sheet images, the local buckling positions show a clear trend. Note the 
yellow color is the original color of the specimen and the white color signifies fiber delamination and face-sheet buckling. For the panel with $0 \mathrm{kN}$ pre-loading, there is no buckling on the front face. For the panel with $15 \mathrm{kN}$ pre-loading, the buckling only occurred at one position. For the panel with $25 \mathrm{kN}$ pre-loading, buckling occurred at two positions beside the center of the specimen. Those white areas at the end of the specimen are not due to local buckling induced by the pre-loading. It is due to the collision between the specimen and shock tube during the blast loading process. From the side view images, the core crack and delamination between the core and face sheets also increase with the increase of the in-plane pre-loading.
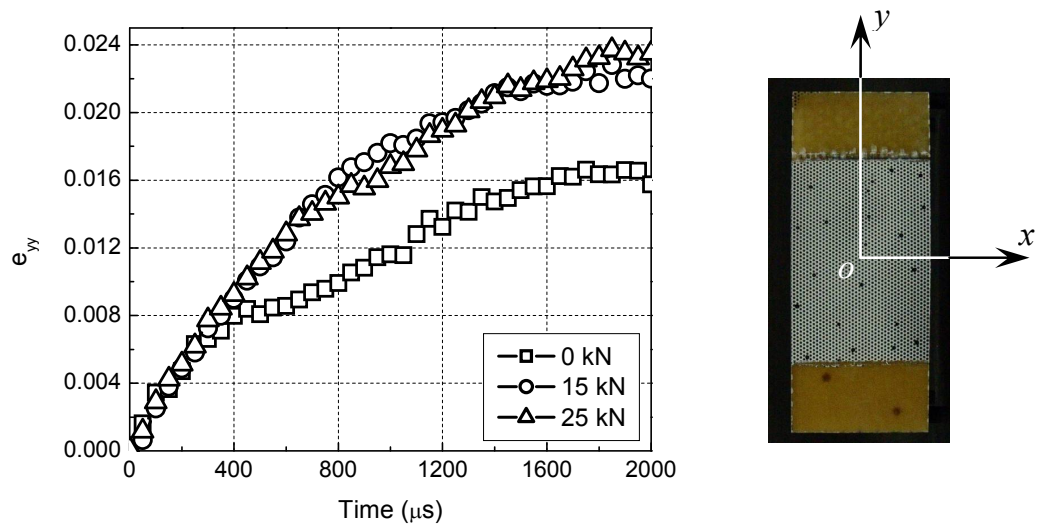

Fig. 8. In-plane strain on the back face.

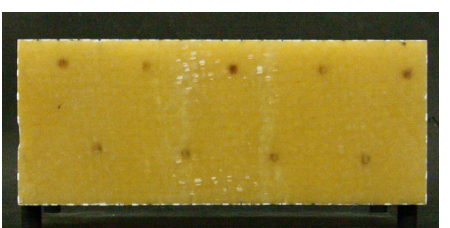

$0 \mathrm{kN}$

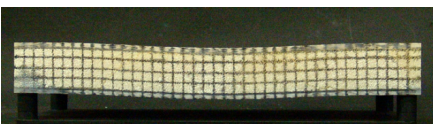

$0 \mathrm{kN}$

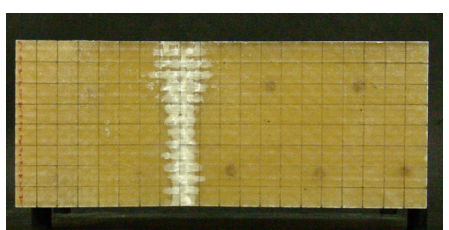

$15 \mathrm{kN}$

Front face

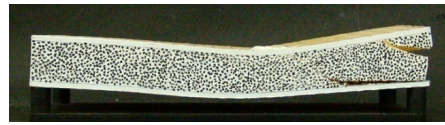

$15 \mathrm{kN}$

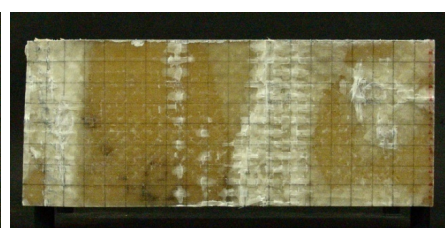

$25 \mathrm{kN}$

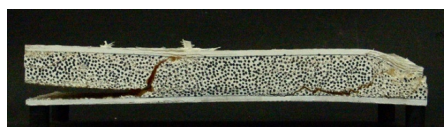

$25 \mathrm{kN}$

Side view

Fig. 9. Post mortem images of sandwich composites

\section{Summary and conclusion}

Sandwich composites, with E-glass Vinyl Ester composite face sheet and CoreCell ${ }^{\mathrm{TM}}$ P600 foam core, were in-plane pre-stressed prior to being subjected to a transverse shock wave loading. Three levels of pre-loading were chosen to study the effect of pre-stresses on the dynamic behavior of the sandwich composites. The results show that the pre-stresses induced the local buckling in the front face during the blast loading process. It weakened the sandwich composites, increased the back face deflection and in-plane strain of the back face-sheet and consequently reduced the blast resistance of the sandwich composites. 


\section{Acknowledgement}

The authors kindly acknowledge the financial support provided by Dr. Yapa D. S. Rajapakse, under Office of Naval Research (ONR) Grant No. N00014-04-1-0268 and the support provided by the Department of Homeland Security (DHS) under Cooperative Agreement No. 2008-ST-061-ED0002. Authors also thank Dr. Stephen Nolet and TPI Composites for providing the facility for fabricating the materials used in this study.

\section{References}

1. T. Yao. Marine Structures, 16,1-13 (2003)

2. S. Heimbs, S. Heller, P. Middendorf, F. Hahnel, J. Weiße, International Journal of Impact Engineering, 36, 1182-1193 (2009)

3. C.T. Sun, J.K. Chen. Journal of Composite Materials, 19, 490-504, (1985)

4. I.H. Choi. Composite Structures, 86, 251-257 (2008)

5. F. Chen, T. Yu. Advances in Engineering Plasticity, 177, 255-260 (2000)

6. http://www.gurit.com

7. E. Wang, N. Gardner, A. Shukla, International Journal of Solids and Structures, 46, 3492-3502 (2009) 